of the milk supply. It is, however, advantageous for the first infection to take place before adult life is reached, because of the partial immunity which may result. The evidence obtained from tuberculin tests in London school children suggests in fact that tuberculisation occurs chiefly in later childhood and adolescence, that is, when the principal activities of the individual are away from home.

It is hoped that further work will result in an answer to the question as to whether tuberculin sensitisation is decreasing in the population, following the improvement in general hygiene and control of tuberculosis. It is also to be hoped that an altogether satisfactory method of prophylactic immunisation will have been developed before the incidence of infection has fallon so much that the general population finds itself in the precarious unprotected state of a nontuberculised race.

\title{
Winds and Weather on the Coasts of India
}

$\mathrm{M}^{\mathrm{B}}$ R. S. BASU, of the Marine Section of the India Meteorological Department, Poona, has pre. pared a useful handbook on the winds and weather off the Indian coasts.* It is based, presumably, largely upon the logs of steamers of the merchant service voyaging in Indian waters, as well as on the work of meteorologists-notably Sir John Eliotwho have made a special study of the cyclones of this region, and is intended to be of service to Indian seamen. Assuming that the standard of accuracy to be expected of a professional meteorologist with extensive sources of trustworthy information has been maintained, this book should fulfil admirably the purpose for which it was written.

The most dangerous weather phenomenon with which the Indian seaman has to concern himself is of course the tropical cyclone. Tropical cyclones do not exhibit quite the infinite diversity of character shown by the cyclonic depressions of the North Atlantic, for they are definite vortices conforming to a fairly definite type. It is possible, therefore, to frame certain general principles that should be followed by a seaman who wishes to avoid exposing the vessel in his charge to the full fury of the inner circle of winds that so often attain to the full force of a hurricane. A special chapter is devoted to this * India Meteorological Department. Winds, Weather and Currents on the Coasts of India and the Laws of Storms. Pp. ili +51 and 18 plates. (Calcutta: Gov. of India Central Pub. Branch, 1931.) 2.6 R8. ; problem, and contains hints as to how the exchange of weather information by radio between ships, together with the utilisation of the official weather reports issued by radio, can help in the navigational problem that arises when a ship approaches sufficiently near to a cyclone.

Another source of danger is the 'Nor'wester', a thunder-squall of early summer that is believed to have given rise to winds of more than a hundred miles an hour. It is primarily a land phenomenon, but is felt sufficiently far out to sea-70-80 miles out, according to the account of it given in the second chapter of the work - to be a menace in the Bay of Bengal.

In addition to information about the more violent weather phenomena, there is much useful matter relating to ordinary local winds and currents and their seasonal variations, and to tides. The last chapter describes the system of visual storm warnings in force throughout Indian waters.

The handbook is well arranged; the standard of printing is adequate, while the maps are clear in spite of their small size. It is not easy for a reviewer in Great Britain to accept the Director-General of Observatories' request for practical suggestions for increasing the usefulness of future editions-unless of course it is proposed to increase its length, in which case much additional information about local peculiarities in the weather could doubtless be in cluded.

E. V. N.

\section{Electric Discharge in Gas at Low Pressure}

$\mathrm{D}^{\mathrm{R}}$ R. I. LANGMUIR presented an interesting review of the electrical properties of the discharge in gas at low pressure, at the recent International Electrical Congress held at Paris. The advances made in this field in the last nine years, which have completely revolutionised our outlook, have come largely from his laboratory and from that of Prof. K. T. Compton. In his recent paper, Dr. Langmuir confined himself to a statement of the more important mathematical relations which have been developed to give a starting point, somewhat simplified still in comparison with reality, for the investigation of discharges. In these there are two fundamental conceptions, that of a 'sheath' and that of a 'plasma'. Sheaths are found in general on the surfaces of electrodes or on the walls of the tubes, and are essentially regions in which there is a strong separation of charges of one sign. In practice these are usually positive, but by control of the potential of the solid boundary, they may be made of the opposite sign. The potential within them is governed by the well-known Poisson equation for the divergence of the electric intensity, and the currents across them determined chiefly by the rate at which particles from the main discharge diffuse to their boundaries.

The plasma is, on the contrary, a region in which the concentrations of electrons and positive ions are almost equal and opposite, and usually both large, of the order of $10^{8}$ to $10^{13}$ per c.c. It has thus a high conductivity, in distinction to the sheaths, and almost invariably in the discharges studied by $\mathrm{Dr}$. Langmuir, has exhibited the peculiarity that the dis. tribution of velocities amongst the electrons in it has been Maxwellian, with a temperature between $5000^{\circ}$ and $100,000^{\circ}$. The determination of these temperatures, and the simultaneous analysis of other features of the plasma, is perhaps the most valuable contribution to a more general theory of discharges from this work, and can be accomplished by taking the currentvoltage characteristic curves for an exploring electrode. At the present time, the chief advances are being made as a result of the departures which have been observed from Dr. Langmuir's original theory of exploring electrodes, and it is clear that the conception of an electron temperature will have to be modified in certain cases.

It is interesting to notice that there are two distinct reasons why parts of a discharge tube may be nonluminous, or almost so. One is, that a sheath is present; and the other, that although in a plasma, which is usually brightly luminous, the discharge is being carried by diffusion, often in a reversed electric field, so that the electrons are not acquiring sufficient energy to excite or ionise the molecules of gas. 